\title{
Evaluating the color change of different types of composite resins subjected to zoom! $®$ in-office bleaching
}

\begin{abstract}
This study was conducted to determine the color change of 3 types of nano-filled composite resins subjected to in-office bleaching (Zoom! ${ }^{\circledR}$ gel material 25\% $\mathrm{H}_{2} \mathrm{O}_{2}$ ). 20 specimen's discs with the dimensions $5 \mathrm{~mm}$ in diameter and $2 \mathrm{~mm}$ in thickness were prepared from each tested material resembling 3 tested groups: Beautiful II, Ceram X mono and IPS Empress Direct composite resins. The discs were polished and stored in distilled water at $37^{\circ} \mathrm{C}$ for one week. Then, these were exposed to Zoom! ${ }^{\circledR}$ in-office bleaching. Colorimetric measurements were performed in the 4 different sessions, before bleaching, two weeks, 4 months and two years after bleaching (resembling 4 subgroups each of 5 discs). Data was collected and statistically analyzed using SPSS version 20 .
\end{abstract}

Results: There was a significant difference between the tested materials, regarding different color parameters $\mathrm{L}^{*} \mathrm{a}^{*}$ and $\mathrm{b}^{*}$ and color change $\Delta \mathrm{E}$. A significance difference was also recorded between the different sessions of color measurements.

Conclusions: It was concluded that the tested bleaching agent affected the color of all materials, and the time was an effective factor in the color change.

Keywords: in-office bleaching, beautiful II, ceram X mono, IPS empress direct, composite resins
Volume 9 Issue I - 2018

\author{
Ameer HH AL-Ameedee ${ }^{1,2}$ \\ 'Department of Dentistry, Beirut Arab University, Lebanon \\ ${ }^{2}$ Department of Dentistry, Babylon University, Iraq
}

Correspondence: Ameer HH AL-Ameedee, Department of Dentistry, Beirut Arab University, Lebanon,

Email ameeralameedee@gmail.com

Received: August 19,2017 | Published: January 10, 2018

\section{Introduction}

Beauty is a combination of qualities that delight the sight, other senses or the mind. Today, because of recent introduction and production of materials science and sophisticated dental techniques, better esthetics \& improved durability of a restoration is achieved. It was found that color maintenance throughout the functional lifetime of restorations which is an indicator for the durability of a treatment. In addition color match is one of the most important characteristics of esthetic restorative materials. ${ }^{1,2}$ Esthetic materials are now placed with minimal invasive techniques, to restore lesions or discolored teeth used to be treated previously with different approaches including crowns, direct and indirect veneers or most conservatively by bleaching. ${ }^{3}$ The public as a conservative and economical method of improving the tooth appearance has received bleaching systems. Currently several bleaching systems are introduced in the market involving in-office bleaching, home-bleaching and over-the counter bleaching products. ${ }^{4-6}$ Chemical methods are most recommended for tooth bleaching. Hydrogen peroxide is a common bleaching agent usually used for in-office treatment with high concentration (30-35\%). Several studies have indicated a morphologic change in the tooth surface after treatment with $10 \%$ carbamide peroxide or $30 \%$ hydrogen peroxide bleaching systems. ${ }^{7-9}$ Others indicated that these chemicals did not affect the sound tooth surface morphology. ${ }^{10-13}$ However, the restored teeth should be considered in the investigations. A limited number of studies have reported the color change of tooth-colored restorative material due to bleaching treatments. These studies used varied concentrations of bleaching products, durations of exposure and testing materials. ${ }^{14,15}$ The type of an esthetic restoration in terms of composition, organic and inorganic phase has been detected as a crucial factor for the degree of color and surface alternations induced by the bleaching products. ${ }^{16-22}$ Resin materials, which are the most commonly used esthetic restorations, are especially more prone to chemical alternation compared to inert metal or ceramic. ${ }^{23,24}$ Composite resins tend to discolor teeth due to their resin matrix, hydrophilicity and water adsorption properties. Previous studies have reported that the color changes of composites resulting from $10 \%$ carbamide peroxide were similar to those of the composites stored in water and were undetectable to the human eye. ${ }^{14,15}$ Thus, composites with their excellent aesthetic properties may change their initial color over time because of surface and marginal staining, as well as, internal material deterioration. ${ }^{25}$ However many reports concerning the effect of in-office bleaching on natural teeth and its effects on tooth colored composite resins are not yet fully explained. ${ }^{26}$ Discoloration had been evaluated with various instruments as instrumental colorimetric and stereomicroscope using the CIE (Comission Internationale de l'Eclairage) $\mathrm{L}^{*} \mathrm{a}^{*} \mathrm{~b} *$ color system, which is developed for characterization of colors based on human perception ${ }^{(27)}$. This system expresses $\Delta \mathrm{E}$ as a relative color change between successive color measurements. It is generally agreed that a value of $\Delta \mathrm{E} \geq 3.3$ is considered clinically perceptible. However the major parameter causing the color change was found to be $\mathrm{L}^{*}$ rather than chroma $\left(\mathrm{a}^{*}\right.$ and $\left.\mathrm{b}^{*}\right){ }^{28}$ Thus, this study was conducted to determine the color change of three types of nanofilled composite resins subjected to in-office bleaching technique using Zoom! ${ }^{\circledR}$ bleaching material. CIE L* $a^{*} b^{*}$ color system was selected for color determination. The null hypothesis was that the color change of the tested materials would respond similarly to the bleaching agent. 


\section{Materials \& methods}

\section{Preparation of specimens}

A total of 60 discs were prepared with $5 \mathrm{~mm}$ in diameter and $2 \mathrm{~mm}$ in thickness in a Teflon cylindrical mold, twenty discs of each type of tested composite resin (Table 1). The shade was standardized for all specimens $\left(\mathrm{A}_{1}\right)$ as to eliminate this variable. The composite was applied as one increment using a custom-made Teflon mold, and covered by a mylar celluloid strip followed by a glass plate, $200 \mathrm{mg}$ weight for $30 \mathrm{sec}$. The discs were cured from each side for $40 \mathrm{sec}$. using light curing was performed for $40 \mathrm{sec}$ at the top and bottom surfaces using a halogen light curing unit (GNATUS, Fotopolimerizador optilight plus, Brazil) at an intensity of $450 \mathrm{~mW} / \mathrm{cm}^{2}$ which was verified before polymerization by using a radiometer (DXI. So.V.INC. USA). The cured resin specimens were removed from the mold by pushing the Teflon condenser against the bottom. There was further polishing of the disc surface by using medium, fine, and superfine polishing discs (Sof-Lex system; 3M ESPE) with a slow-speed hand piece, rotating in one direction, although the smoothness was obtained with the celluloid strip. All specimens after cleaned followed by a $30 \mathrm{sec}$ Pro'skit ultrasonic cleaner (Pro'skit, SS-802F, China). The specimens were stored in distilled water at $37^{\circ} \mathrm{C}$ for one week to ensure complete polymerization, and then 5 specimens from each tested groups were blotted dry to be subjected to color evaluations were performed using correction evaluation, using Vita Easyshade compact device (VITA Zahnfabrik H. Rauter Gmbh \& Co. KG, Bad Säckingen, Germany). The readings were recorded as control (before bleaching) data. The specimens were then subjected to Zoom! ${ }^{\circledR}$ in-office bleaching gel (Discus Dental Canada, 2830 Argentia Road,Unite 728 Mississauga, 0NL5N-8G4) according to the manufacturer's instructions, the storage medium was replaced on weekly basis using an environmental water bath (BW1. PORTEX Ltd. Hythe Kent. England). The sessions for recording the color measurements preformed before bleaching, two weeks, 4 months, and two years after bleaching are shown in (Table 2). This system allows the numeric definition of a color as well as the difference between two color values obtained using Hunter's equation: $\Delta \mathrm{E}=\left(\mathrm{L}_{1}-\mathrm{L}_{0}\right)^{2}+\left(\mathrm{a}_{1}-\mathrm{a}_{0}\right)^{2}+\left(\mathrm{b}_{1}-\mathrm{b}_{0}\right)^{2} 1 / 2$. The change in color from control compared to the color two weeks after bleaching was calculated as $\Delta \mathrm{E}_{1}$. The change in color 4 months after bleaching compared to two weeks after bleaching was calculated as $\Delta \mathrm{E}_{2}$ while the change in color two years after bleaching compared to 4 months after bleaching was calculated as $\Delta \mathrm{E}_{3}$. Before each assessment the instrument was calibrated according to the manufacturer's recommendations. The discs were mounted at $90^{\circ}$ relative to the light source. For each specimen 5 readings were taken \& mean of $\Delta \mathrm{E}$ was calculated \& recorded. All data was collected, tabulated according to groups \& subgroups to be statistically analyzed. Data were fed to the computer \& analyzed using IBM SPSS software package version 20. Quantitative data was described using mean \& standard deviations. The distributions of quantitative variables were tested normally using Kolmogorov-Smirnov test, Shapiro-Wilk test \& D'Agstino test. Also Histogram \& Q-Q plot were used for vision test. If it revealed normal data distribution, parametric tests were applied. If the data were abnormally distributed, non-parametric tests were used. For abnormally distributed data, comparison between two independent populations was done using Mann Whitney test, while Kruskal Wallis test was used to compare different groups.

Significance test results are quoted as two tailed probabilities. Significance of the obtained results was judged at the $5 \%$ level.

Table I Materials used in the study

\begin{tabular}{|c|c|c|}
\hline Material & Composition & Manufacturer \\
\hline \multirow{8}{*}{ Beautiful II G I } & Bis phenyl glycidyl Dimethacrylate (Bis-GMA) & \\
\hline & 7.5\% triethylenglycol Dimethacrylate (TEGDMA) & \\
\hline & $5 \%$ Aluminofluoro & Shofu Dental corporation USA \\
\hline & $70 \% \mathrm{AL}_{2} \mathrm{O}_{3}$ (borosilicate glass) & \\
\hline & DL-Camphorquinone & \\
\hline & Methacrylate modified polysiloxone. & De Tray \\
\hline & Di methacrylate resin. & Dentsply \\
\hline & Ba-Al-borosilicate glass. & Germany \\
\hline \multirow{7}{*}{ Ceram. X. mono G II } & $70 \%$ pyrogenic $\mathrm{Sio}_{2}$ & \\
\hline & $57 \%$ camphorpuinone & \\
\hline & ethyl-4-dimethylamino benzoate & \\
\hline & UV stabilizer & \\
\hline & butylated hydroxyl to luene & \\
\hline & Paste of Dimethacrylates, & Ivochr.Vivadent \\
\hline & Copolymer $20-21 \%$ wt. & USA \\
\hline \multirow{4}{*}{ ISP Empress Direct G III } & barpum glass $77.5-79 \%$ wt. & \\
\hline & ytterbium trifluoride $(550 \mathrm{~nm})$ & \\
\hline & Initiators & \\
\hline & Stabilizers and pigments & \\
\hline
\end{tabular}


Table 2 Grouping and sessions for recording

\begin{tabular}{|c|c|c|c|c|}
\hline \multirow{2}{*}{$\begin{array}{l}\text { Groups } \\
\text { GI }(n=20)\end{array}$} & \multicolumn{4}{|c|}{ Subgroups and sessions for recording the color changes measurements } \\
\hline & Before bleaching & Two weeks after & 4 months after & 6 months after \\
\hline G II (n=20) & Immersion in distilled & bleaching, $n=5$ & bleaching, $n=5$ & bleaching, $n=5$ \\
\hline G III $(n=20)$ & water at $37^{\circ} \mathrm{C}$ for one week, $\mathrm{n}=5$ & & & \\
\hline
\end{tabular}

\section{Results}

Data were presented as mean and standard deviation (SD) values. One way ANOVA test was used to compare the color at $\Delta \mathrm{E}_{1}$ data to the color after bleaching in different sessions. Effect of bleaching on color change between the three groups at different time intervals (as a factor of time) revealed a significant effect on color change of each group individually (Table 3). Effect of bleaching on color change within the group (as a factor of time), regarding GI, there was a significant effect at all-time interval. Regarding GII, there was a significant effect at all-time interval. Regarding GIII, there was a no significant effect at $\Delta \mathrm{E}_{2}$. However, there was significance effect at $\Delta \mathrm{E} 3$. Comparison between the three groups at $\Delta \mathrm{E}_{1}$ revealed that GI there was significant color change. However, GII and GIII no significant difference at $\Delta \mathrm{E}_{1}$. No significant differences among the three groups at $\Delta \mathrm{E}_{2}$ and $\Delta \mathrm{E}_{3}$ (Table 3). Regarding the color change, comparing the color change resembled in $\Delta \mathrm{E}$ of each group using the $\mathrm{F}$-test. It was found that a highly significant difference was recorded in GI and significant in each GII and GIII tested group, GI and GII revealed statistically significant changes in color differences $(\Delta \mathrm{E})$ after bleaching at all tested time intervals. However, GIII did not show color differences $(\Delta \mathrm{E})$ changes except at $\Delta \mathrm{E}_{3}$ tested time interval (Table 3 ). However, concerning $\Delta \mathrm{E}$ the significant difference among the three tested groups was recorded only $\Delta \mathrm{E}_{1}$ to visual detection of the difference between three tested groups a bar graph was drawn (Figure 1). The highest mean value was seen in GI at $\Delta \mathrm{E}_{1}$, and the lowest mean value was seen in GII at $\Delta \mathrm{E}_{3}$ recording that the material is an effective variable in the color change (Figure $1 \&$ Table 3 ). To compare the control or baseline data to the different sessions of color evaluation after bleaching Table 5 represented LSD comparison. A significant difference was recorded in both GI \& GII. In Group I the significance is present between before bleaching (control) data versus all periods of color evaluation. Ingroup II all the significance is present between before bleaching vs. two weeks after bleaching (Table $4 \& 5$ ).

\section{Bar graph representing mean color values of the 3 groups in different color recording sessions}

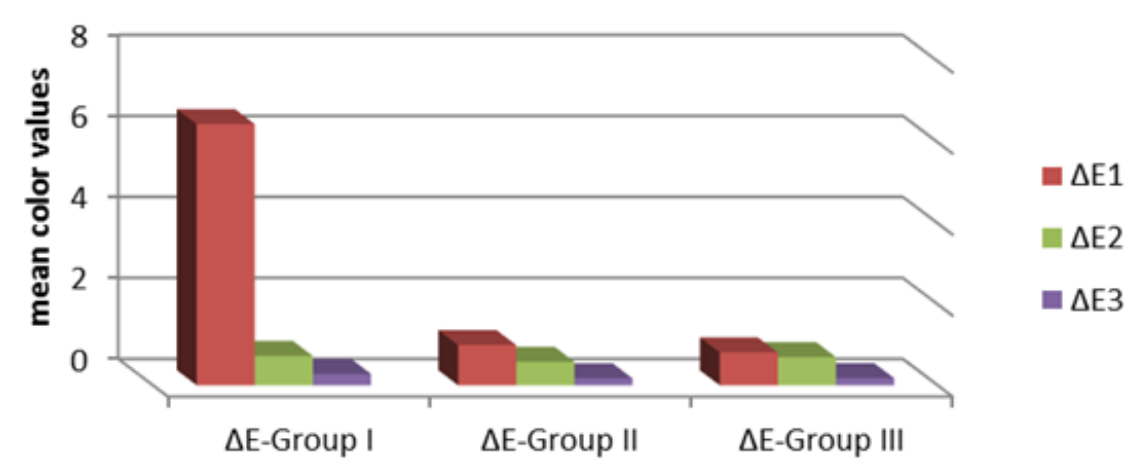

Figure I Bar graph representing mean color values $(\Delta \mathrm{E})$ of the three groups in different color recording sessions.

Table 3 Descriptive statistical study of color changes $(\Delta E)$ for all the tested groups $(n=5)$

\begin{tabular}{lllll}
\hline Group & $\Delta \mathbf{E I}$ & $\Delta \mathbf{E} 2$ & $\Delta \mathbf{E} 3$ & F-test $(\mathbf{p})$ \\
\hline B. Group I $\mu \pm \sigma$ & $6.453 \mathrm{a} \mathrm{I} \pm 0.306$ & $0.725 \mathrm{~b} 3 \pm 0.843$ & $0.277 \mathrm{~b} 4 \pm 0.297$ & $398.7(\mathrm{P}<0.0 \mathrm{I}) * *$ \\
C. Group II $\mu \pm \sigma$ & $0.994 \mathrm{a} 2 \pm 0.639$ & $0.579 \mathrm{~b} 3 \pm 0.397$ & $0.17 \mathrm{c} 4 \pm 0.106$ & $8.843(\mathrm{P}<0.05)^{*}$ \\
E. Group III $\mu \pm \sigma$ & $0.73 \mathrm{~b} 2 \pm 0.60 \mathrm{I}$ & $0.694 \mathrm{~b} 3 \pm 0.633$ & $0.177 \mathrm{c} 4 \pm 0.072$ & $3.787(\mathrm{P}=0.04)$
\end{tabular}

*The mean difference is significant at the 0.05 level

**The mean difference is highly significant at the 0.01 level

Different letter in same row= significant differences

Different number in same column= significant differences 
Table 4 Statistical analysis between groups in different color recording sessions

\begin{tabular}{|c|c|c|c|c|c|c|}
\hline & & T0- $N=5$ & TI $-\mathbf{N}=5$ & T2- $N=5$ & T3- $N=5$ & F-test (p) \\
\hline \multirow[t]{3}{*}{ B.Group I $\mu \pm \sigma$} & $L^{*}$ & $83.151 \pm 0.51$ & $80.07 I \pm 0.05$ & $80.71 \pm 0.70$ & $80.491 \pm 0.88$ & $47.07(\mathrm{p}<0.0 \mathrm{I})^{* *}$ \\
\hline & $a^{*}$ & $-0.37 I \pm 0.17$ & $0.87 I \pm 0.05$ & $0.621 \pm 0.36$ & $0.55 I \pm 0.314$ & $45.25(\mathrm{p}<0.0 \mathrm{I}) * *$ \\
\hline & $b^{*}$ & $20.57 I \pm 0.24$ & $|5.06| \pm 0.05$ & $|5.22| \pm 0.16$ & $15.161 \pm 0.15$ & $28.02(\mathrm{p}<0.01)^{* *}$ \\
\hline \multirow[t]{2}{*}{ C.Group II $\mu \pm \sigma$} & $\mathrm{L}^{*}$ & $82.512 \pm 0.73$ & $82.772 \pm 0.69$ & $82.522 \pm 0.7 \mathrm{I}$ & $82.352 \pm 0.69$ & $0.61(0.615)$ \\
\hline & $b^{*}$ & $15.52 \pm 0.50$ & $15.32 \pm 0.28$ & $|5.3| \mid \pm 0.45$ & $|5.3| \mid \pm 0.45$ & $0.50(0.68)$ \\
\hline \multirow[t]{3}{*}{ E.Group III $\mu \pm \sigma$} & $\mathrm{L}^{*}$ & $79.083 a \pm 0.40$ & $78.893 a \pm 0.44$ & $79.083 a \pm 0.39$ & $79.013 a \pm 0.40$ & $0.83(0.49)$ \\
\hline & $a^{*}$ & $-2.273 a \pm 0.20$ & $-2.223 a \pm 0.24$ & $-2.263 a \pm 0.20$ & $-2.283 a \pm 0.27$ & $0.13(0.94)$ \\
\hline & $b^{*}$ & $12.853 \mathrm{a} \pm 0.53$ & $13.013 a \pm 0.25$ & $12.863 \mathrm{a} \pm 0.54$ & $12.783 a \pm 0.53$ & $0.75(0.75)$ \\
\hline \multirow[t]{5}{*}{ F-Test (p) among 3 groups } & $L^{*}$ & $|5| .6(p<0.0 \mid)^{* *}$ & $179.5(\mathrm{p}<0.01)^{* *}$ & $37.37(\mathrm{p}<0.01)^{* *}$ & $59.44(p<0.01)^{* *}$ & \\
\hline & $a^{*}$ & $622.1(p<0.01)^{* *}$ & $124.7(p<0.01)^{* *}$ & $318.4(\mathrm{p}<0.01)^{* *}$ & $410.4(p<0.01)^{* *}$ & \\
\hline & $b^{*}$ & $788(\mathrm{p}<0.01)^{* *}$ & $324.7(\mathrm{p}<0.01)^{* *}$ & || $\mid .6(p<0.01)^{* *}$ & || $8.5(p<0.01)^{* *}$ & \\
\hline & $\Delta \mathrm{E}$ & & $\Delta \mathrm{E}_{1}$ & $\Delta \mathrm{E}_{2}$ & $\Delta \mathrm{E}_{3}$ & \\
\hline & $\mathrm{F}$ & & $362.4(p<0.01)^{* *}$ & $0.139(0.87 I)$ & $1.017(0.375)$ & \\
\hline
\end{tabular}

*The mean difference is significant at the 0.05 level

**The mean difference is highly significant at the $0.0 \mathrm{I}$ level

Table 5 LSD test to compare the changes in color space system within groups after the alteration by $\mathrm{H}_{2} \mathrm{O}_{2}$ for two years' time follow up

\begin{tabular}{|c|c|c|c|c|}
\hline & & $\begin{array}{l}\text { Before Bleaching Vs Two Weeks } \\
\text { After Bleaching }\end{array}$ & $\begin{array}{l}\text { Before Bleaching Vs } 4 \text { Months } \\
\text { After Bleaching }\end{array}$ & $\begin{array}{l}\text { Before Bleaching Vs Two } \\
\text { Years After Bleaching }\end{array}$ \\
\hline \multirow{3}{*}{ Group I P-value } & $L^{*}$ & $\mathrm{P}<0.0 \mathrm{I} * *$ & $\mathrm{P}<0.0 \mathrm{I} * *$ & $\mathrm{P}<0.0 \mathrm{I} * *$ \\
\hline & $a^{*}$ & $\mathrm{P}<0.0 \mathrm{I} * *$ & $\mathrm{P}<0.0 \mathrm{I} * *$ & $\mathrm{P}<0.0 \mathrm{I}^{* *}$ \\
\hline & $b^{*}$ & $\mathrm{P}<0.0 \mathrm{I} * *$ & $\mathrm{P}<0.01 * *$ & $\mathrm{P}<0.0 \mathrm{I} * *$ \\
\hline \multirow{3}{*}{ Group IIP-value } & $\mathrm{L}^{*}$ & $0.048^{*}$ & 0.34 & $0.7 \mathrm{I}$ \\
\hline & $a^{*}$ & $0.049 *$ & 0.44 & 0.85 \\
\hline & $b^{*}$ & 0.22 & 0.96 & 0.75 \\
\hline
\end{tabular}

*The mean difference is significant at the 0.05 level

**The mean difference is highly significant at the 0.01 level

\section{Discussion}

Discoloration of composite resins remains a major cause of the esthetic failure of materials. Such discoloration may be caused by intrinsic or extrinsic factors. The discoloration may involve the resin material itself. To ensure excellent esthetics, it is necessary for tooth colored restorations to maintain intrinsic color stability and resistance to surface staining. ${ }^{29}$ Currently, according to the resin composite surface color it was found that evaluating the color before bleaching GI showed the statistical significant highest mean color value followed by GII, while GIII had the statistical significant lowest mean color value. After bleaching the color was evaluated in 3 different sessions. It was found that $\mathrm{G} I$ had the highest $\Delta \mathrm{E}$ mean value at $\Delta \mathrm{E}_{1}$, while $\mathrm{G}$ II showed the lowest mean $\Delta \mathrm{E}$ value at $\Delta \mathrm{E}_{3}$. These findings illustrated that bleaching agents used affected the color change of each tested group significantly. This was in accordance to Erim \&
Ulukapi et al., ${ }^{29}$ who stated that the bleaching agents caused adverse effects to the tooth/restoration interface. The results collected in the present investigation showed significant differences between three tested groups in color change which might be related to differences in chemical composite size, distribution of filler particles. A larger area of interface between particle matrixes composite possibly makes it more susceptible to discoloration. ${ }^{31,32}$ Others explained that bleaching treatment led to surface dissolution in the materials. Tiny pores on the surface, resulting from the matrix dissolution, occupied by air or saliva. The differences of optical properties among the materials, air, and water increased the reflectance on the surface. ${ }^{33-35}$. Despite the increase in brightness that was evident for tested composites, this parameter alone was not conclusive or decisive for description of color, since color can only be described in three dimensions. Lim et al. ${ }^{36}$ concluded that the correlation between the contents of color is moderate, despite a direct relationship between content loading, 
scattering coefficient and reflected light and the change in $\Delta \mathrm{E}$ mean values. This was true in the current findings showing a decrease in mean $\Delta \mathrm{E}$ values at $\Delta \mathrm{E}_{3}$ for GI and an increase in mean $\Delta \mathrm{E}$ values for both groups II and III reaching the maximum values at $\Delta \mathrm{E}_{3}$. This was also supported by other studies, ${ }^{37-48}$ who stated that micro cracks and micro voids located at the interface between the filler and the matrix are the most likely penetration pathways for stain. The roughness of the surface caused by wear and chemical degradation may also affect gloss and consequently increase the extrinsic staining. ${ }^{41,42}$ This in this vitro study has several limitations. One is the lack of thermo-cycling that could influence the degree of total color change. The difference in thermal expansion coefficient or thermal conductivity coefficient between filler particles and resin matrix may result in a difference in thermal volumetric changes between resin matrix and filler particles. It was also reported that water absorption would be accompanied by hygroscopic expansion in the resin matrix and filler phase, thereby enhancing the weakening filler matrix interface. This should be considered in future research.

\section{Conclusion}

The Zoom! ${ }^{\circledR}$ In-office bleaching gel affects the color change of tested restorative materials in a different way.

The time affected the color changes of materials tested.

\section{Acknowledgments}

None.

\section{Conflicts of interest}

The author declares that there is no conflict of interest.

\section{References}

1. Aravamudhan K, Rakowski D, Fan PL. Variation of depth cure and intensity with distance using LED curing lights. Dent Mater. 2006;22(11):988-994.

2. Asmussen E. Factors affecting the color stability of restorative resins. Acta Odontol Scand. 1983;41(1):11-18.

3. Kusel G, Kastali S. Tooth whitening efficacy and safety: a randomized and controlled clinical trial. Compend Contin Edu Dent. 2000;29 Suppl:S16-S21.

4. Crim GA. Pre-restorative bleaching: effect on microleakage of class V cavities. Quintessence Int. 1992;23(12):823-825.

5. Haymann HO. Tooth whitening: facts and fallacies. $B r$ Dent $J$. 2005;198(8): 514.

6. White DJ, Kozak KM, Zolad Z, et al. Peroxide interactions with hard tissues effects on surface hardness and surface/subsurface ultra-structural properties. Compend Contin Educ Dent. 2002;23(1A):42-48.

7. Feritas AC, Espejo LC, Brossi SB, et al. AFM analysis of bleaching effects on dental enamel microtopography. Applied Surface Science. 2010;256(9):2915-2919.

8. Cavalli V, Arrais CA, Giannini M, et al. High concentrated carbamide peroxide bleaching agents' effects on enamel surface. J Oral Rehabil. 2004;31(2):155-159.

9. Yeh ST, Su Y, Lu YC, et al. Surface changes and acid dissolution of enamel after carbamide peroxide bleach treatment. Oper Dent. 2005;30(4):507-515.
10. Cobankara FK, Unlu N, Altinoz HC, et al. Effect of home bleaching agents on the roughness and surface morphology of human enamel and dentin. Int Dent J. 2004;54(4):211-218.

11. Justino LM, Tames DR, Demarco FF. In situ and in vitro effects of bleaching with carbamide peroxide on human enamel. Oper Dent. 2004;29(2):219-225.

12. Auschill TM, Barcsay LA, Arweiler NB. Stips versus gel: a clinical comparison of two over-the-counter bleaching system. Schweiz Monatsschr Zahnmed. 2017;17:843-856.

13. Mielczarek A, Klukowska M, Ganowicz M, et al. The effect of strip, tray and office peroxide bleaching systems on enamel surfaces in vitro. Dent Mater. 2008;24(11):1495-1500.

14. Monaghan P, Lim E, Lautenschlager E. Effects of home bleaching preparations on composite resin color. J Prosthet Dent. 1992;68(4):575-578.

15. Cany S, Cehreli Mc. The effect of current bleaching agents on the color of light-polymerized composites in vitro. J Prosthet Dent. 2003;89(5):474-478.

16. Philipsen HP, Reichart PA. Adenomatoid odontogenic tumour: facts and figures. Oral Oncol. 1999;35(2):125-131.

17. Garg D, Palaskar S, Shetty VP, et al. Adenomatoid odontogenic tumor-hamartoma or true neoplasm: a case report. J Oral Sci. 2009;51(1):155-159.

18. Philipsen HP, Birn H. The adenomatoid odontogenic tumour. Ameloblastic adenomatoid tumour or adenoameloblastoma. Acta Pathol Microbiol Scand. 1969;75(3):375-398.

19. Deveraux QL, Reed JC. IAP family proteins-suppressors of apoptosis. Genes Dev. 1999;13(3):239-252.

20. Takahashi R, Deveraux Q, Tamm I, et al. A single BIR domain of XIAP sufficient for inhibiting caspases. J Biol Chem. 1998;273(14):7787-7790.

21. Schmidt SM, Schag K, Muller MR, et al. Survivin is a shared tumorassociated antigen expressed in a broad variety of malignancies and recognized by specific cytotoxic T cells. Blood. 2003;102(2):571-576.

22. Hanahan D, Weinberg RA. The hallmarks of cancer. Cell. 2000;100(1):57-70

23. Lowe SW, Lin AW. Apoptosis in cancer. Carcinogenesis. 2000;21(3):485-495.

24. Adida C, Crotty PL, Mc Grath J, et al. Developmentally regulated expression of the novel cancer anti-apoptosis gene survivin in human and mouse differentiation. Am J Pathol. 1998;152(1):43-49.

25. Wynford Thomas D. Oncogenes and anti-oncogenes; the molecular basis of tumour behaviour. J Pathol. 1991;165(3):187-201.

26. Weinberg RA. Oncogenes, antioncogenes, and the molecular bases of multistep carcinogenesis. Cancer Res. 1989;49(14):3713-3721.

27. Velculescu VE, Madden SL, Zhang L, et al. Analysis of human transcriptomes. Nat Genet. 1999;23(4):387-388.

28. Andersen MH, Svane IM, Becker JC, et al. The universal character of the tumor-associated antigen survivin. Clin Cancer Res. 2007;13(20):5991-5994.

29. Gianani R, Jarboe E, Orlicky D, et al. Expression of survivin in normal, hyperplastic, and neoplastic colonic mucosa. Hum Pathol. 2001;32(1):119-125.

30. Ulukapi H, Benderli Y, Ulukai I. Effect of pre-and post-operative bleaching on marginal effect of leakage of amalgam and composite restorations. Quintessence Int. 2003;34(7):505-506. 
31. Yannikakis SA, Zissis Aj, Plyzois GL, et al. Color stability of provisional resin restorative materials. The Journal of Prosthetic Dentistry. 1998;80(5):533-539.

32. Ergucu Z, Turkun LS, Aladag A. Color stability of nano composites polished with one-step systems. Oper Dent. 2008;33(4):413-420.

33. Plotino G, Buonol L, Grande NM, et al. Non vital tooth bleaching: a review of the literature and clinical procedures. J Endod. 2008;34(4):394-407.

34. Gokay O, Yilmaz F, Akin S, et al. Penetration of the pulp chamber by bleaching agents in teeth restored with various restorative materials. $J$ Endod. 2000;26(2):92-94.

35. Monaghan P, Lin E, Lautenschlager E. Effects of home bleaching preparations on composite resin color. The Journal of Prosthetic Dentistry. 1992;68(4):575-578.

36. Lim YK, Lee YK, Lim BS, et al. Influence of filler distribution on the color parameters of experimental resin composites. Dent Mater. 2008;24(1):67-73.
37. Hufschmidt D, Bahnemann D, Testab JJ, et al. Enhancement of the photocatalytic activity of various $\mathrm{TiO} 2$ materials by platinwasation. $J$ Phys Chem. 2002;148:223-231.

38. Menéndez Flores VM, Friedmann D, Bahnemann DW. Durability of $\mathrm{AgTiO}_{2}$ Photocatalysts Assessed for the Degradation of Dichloroacetic Acid. International Journal of Photoenergy. 2008;13:1-12.

39. Wasmail AA, Bahnemann DW, Robben L, et al. Palladium doped porous titania photo catalysts: impact of mesoporous order and crystallinity. Chem Mater. 2010;22(1):108-116.

40. Ayad FA, Mohammed B Alqaraguly. Adsorption and Photocatalytic degradation of crystal violet dye in the presence of different metals doping on $\mathrm{TiO}_{2}$. Journal of Applicable Chemistry. 2013;2(2):291-303.

41. Yu H, Wegehaupt FJ, Wiegand A, et al. Erosion and abrasion of tooth-colored restorative materials and human enamel. $J$ Dent. 2009;37(12):913-922.

42. Brook AH, Smith RN, Lath DJ. The clinical measurement of tooth color and stain. Int Dent J. 2007;57(5):324-330. 